https://doi.org/10.48009/2_iis_2010_199-207

\title{
FORMAL INQUIRY SYSTEMS: AN INQUIRY PROFILE FOR PROJECT MANAGEMENT?
}

\author{
Roy A. Boggs, Florida Gulf Coast University, rboggs@ fgcu.edu \\ Bennett Hammer, Florida Gulf Coast University, bennethammer@ comcast.net
}

\begin{abstract}
The basic concepts of inquiry systems have long been applied to business systems, including behavior and management systems, environmental structures, public policy and ethical issues. Most of these concepts have, however, been applied to an historical knowledge of inquiry systems; or, as in the case of technology and information systems, have presented mainly mathematical calculations and formulas for the development of tools and applications. One very important factor that has often been overlooked is a formal approach to the involvement of people and human factors in inquiry systems development. A next generation inquiry model is proposed to extend inquiry systems thinking to information resources analysis and specifically to project management. It is designed as a pedagogical tool with which to begin class discussions and as a basis for applied research.
\end{abstract}

Keywords: information resources analysis, project management, systems thinking, systems analysis

\section{INTRODUCTION: Putting the Pieces Together}

The concepts of learning organizations and system design began for all practical purposes with $\mathrm{C}$. West Churchman's The Design of Inquiring Systems: Basic Concepts of Systems and Organizations (1971). $\mathrm{He}$ interpreted the writings of the philosophers Leibniz, Locke, Kant, Hegel and Singer in the context of designing inquiry systems. The concepts of inquiry systems which he introduced in this work have been studied and implemented in many sciences, including public policy (McIntyre, 2003), environmental sciences (Richardson, 2001), management systems, and behavioral and religious sciences (Eriksson, 2003). However, technology and information systems' disciplines have lately focused on mathematical calculations and formulas to develop new tools and applications to solve business problems. It has involved the theoretical foundations of information and computation along with its applications in computer systems, and it has driven a

Volume XI, No. 2, 2010 significant trend of continuous improvement, not only in processes and operations, but also in supporting making-decisions and competitive strategies (Davis, Fuller, Tremblay, \& Berndt, 2006). These concepts provide a historical knowledge of inquiry systems, but no science to incorporate inquiry systems analysis. There is one very important factor that is missing which will become the main focus for future development of new systems; it is the involvement of people and the human factor to which Churchman refers in his work. Unfortunately, very little attention has been given in literature to develop an understanding of human capabilities critical for system design in organizations with an emphasis on creating efficient systems.

The seminal theoretical works of Churchman (1971), Mitroff (1974) and Richardson, Courtney \& Paradice (2001) are reviewed in detail and summarized in table format (Table 1). This overview is then used as a platform for a new model for information resources analysis research, incorporating the advances in information systems thinking by Senge (1993) and Malhotra (2000) (Table 2). The results of the model reveal a series of assumptions on how characteristics of systems thinking can be utilized for information resources analysis and, for example, better manage systems development. An example would apply to the PMP Project Management Framework module of Project Human Resource Management Process: Team Assembly and Team Management. It provides a basis for better employing and understanding team structures when designing an information resources analysis process.

The model (Table 2) is entitled 'An Integrated Adaptive Inquiry System - A Model' and is designed as a pedagogical tool with which to begin discussion and as a basis for bringing together different areas of applied research. Its purpose is to begin to structure and to synthesize various avenues of research into a process that makes sense for applied areas of pedagogy and research, such as project management and information resources analysis. It is in three parts, entitled I. Elicitation (identifying individual stakeholders' information profiles), II. Calculation
Issues in Information Systems 
(synthesis of various individuals according to their profiles), and III. Implementation (identifying overall profiles - for example for a project team). Each of these is explained in the following and then integrated into one model.

\section{OVERVIEW}

The following overview is presented under two headings:

1- Formal Inquiry Systems

2- Adaptive Inquiry systems

The first section, Formal Inquiry Systems, is reviewed in some detail, because it is, and has been, the basis for scholarship in many academic disciplines. Each section may be skipped by those who are familiar with research in these areas, although Table 1 can be reviewed for purposes of review and orientation.

\section{OVERVIEW - 1a THEORETICAL DEVELOPMENT: FORMAL INQUIRY SYSTEMS}

The formal inquiry systems presented by Churchman (1971), extended by Mitroff (1974), and then Courtney et al. (1998), are summarized as a basis for building the underlying center piece of the model. These are taken in the order presented by Churchman (Leibnitz, Locke, Kant, Hegel and Singer) and then summarized in Table 1. They are

\section{1- the Analyst (Leibnizian IS)}

According to Churchman, a Leibnizian inquiring system is a closed system with a set of built-in elementary axioms that are used along with formal logic to generate more general fact nets or tautologies (Churchman, 1971). This system, which is rational in nature, mainly relies on the theory of autopsies for its existence. The fact nets are created by identifying hypotheses, with each new hypothesis being tested to ensure that it could be derived from, and is consistent with, the basic axioms. Once so verified, the hypothesis becomes a new fact within the system. The guarantor of the system is the internal consistency and comprehensiveness of the generated facts.

According to Ian Mitroff (1974), the Leibnizian inquiry system is characteristic of formal-deductive systems. It is purely theoretical and emphasizes the

Volume XI, No. 2, 2010 formal, mathematical, logical, and rational aspects of human thought. The Leibnizian inquiry system is strong in consistency, precision, and a lack of ambiguity. It is weak in the same points that make it strong: rigor, precision and logic.

Courtney, Croasdell, and Paradice (1998) explain the Leibnizian inquirer as one who learns by using logical thinking to make decisions of cause and effect. According to Courtney, Croasdell, and Paradice (1998), this inquiry system shows that certain components of a system are used to make new components enabling the system to be recreated. This method uses a closed system; thus it only has the power of knowledge generated internally. Any new changes within the organization must be compatible with the previous policies and procedures. One should not ignore the fact that it is possible and likely that once at a certain level of learning, everything stops and the organization falls behind. Once this happens, it is very difficult to return to high success. Because the inquiry system is closed by definition and there is an assumption of an absolute guarantor within the Leibnizian process, there is not an opportunity to question or refute the guarantor. Therefore, this system relies completely on the accuracy and integrity of the guarantor, which makes the Leibnizian inquiry facts and decision indefensible. Leibnizian inquiry represents an expert systems decision making process. When applying the Leibnizian inquiry system to information technology, a few examples include: an online registration page for an e-newsletter; a shopping cart software application for an online retailer; and a GPS application for use in a car.

\section{2- the Realist (Lockean IS)}

Churchman (1971) defines the Lockean inquiring system as experimental and consensual. It is capable of supporting itself with both an adaptive and a generative method of learning. In contrast to the Leibnizian inquiring systems, the Lockean inquiry system is an open system and can be influenced by elements outside its environment. Empirical information, gathered from external observations, is used inductively to build a representation of the world (Churchman, 1971). It consists of no built-in preconceptions of the world and is set apart from the rest the world by how the learning process occurs. Elementary observations form the input to the Lockean inquirer has a basic set of labels which it assigns to the inputs, and is capable of observing its own process by means of reflection and backwards tracing of labels to the most elementary labels.
Issues in Information Systems 
Agreement on the labels by the Lockean community is the guarantor of the system (Churchman, 1971).

According to Ian Mitroff (1974), the Lockean inquiry system perpetuates the purely sensory and empirical aspects of human knowledge. The primary strength of the Lockean inquiring system is the potential for great amounts of experiential data to be included from a group. Two major weaknesses of Lockean inquiring system are that the experience can be fallible and misleading which leads to assumptions by the guarantor and the potential cost that exists for arriving upon an agreement.

Courtney, Croasdell, and Paradice (1998) explains the Lockean inquiring system as an organization that learns by making observations about society and expressing these observations enabling one to create a conclusion for what has just happened. Lockean inquiring system attempts to build teamwork among the members and come to an agreement with everyone helping to create organizational knowledge. This type of inquiry supports both adaptive and generative learning. These systems are willing to listen to outside opinions for new ideas or ways to look at a given scenario. Lockean inquiring system believes this is why it is possible to see everything that happens in an event. However, because of these factors, the group or guarantor of the system may need to make broad or incorrect assumptions and thus, make the decisions unreliable. Lockean inquiry is best represented by the group decision support system.

\section{3. the Idealist (Kantian IS)}

As defined by Churchman (1971), the Kantian inquiring system is a mixture of the Leibnizian and Lockean inquiry modes in the sense that it contains both theoretical and empirical components. The Kantian inquiring system scans both internal and external environment for true knowledge. The empirical component is capable of receiving inputs, so the system is open. It generates hypotheses on the basis of inputs received. The Kantian inquirer is able to use explicit knowledge and tacit knowledge to consider the many interpretations of inputs. This allows the system to compare incoming knowledge to what is already located in the system memory and to create and incorporate that new knowledge.

Ian Mitroff (1974) explains the Kantian inquiring system to be characteristic of synthetic multimodel systems. Kantian inquiring system is synthetic because it seeks to reconcile the rationale of Volume XI, No. 2, 2010
Leibnizian inquiring system with the empirical of Lockean inquiring system. They are multimodel because they produce at least two alternate models (Mitroff, 1974). Due to its synthetic nature, the greatest strength of Kantian inquiring system is in their ability to counter the weaknesses of the Leibnizian and the Lockean inquiring system. The weaknesses of Kantian inquiring system are due to the multiple models presented. The correct answer is uncertain and not guaranteed in the models presented. The inquirer may not have enough knowledge to choose the appropriate model, and multimodel systems are more costly to operate.

Courtney, Croasdell, and Paradice (1998) view the Kantian inquiring system as a system that uses internal and external environments for creating useful and meaningful knowledge. Kantian inquiring system believes new knowledge is created from existing knowledge which gives it the characteristic of both open and closed systems. Using hunches, intuition, and experience, Kantian based inquiry is able to see variations of inputs. This incoming knowledge is compared to original organizational structure enabling one to create new knowledge. While decisions are made based on open input and consensus, there is no guarantee that the process or guarantor represents the best solution. Decisions are subject to bias and incorrect input of information.

\section{4- the Synthesist (Hegelian IS)}

Churchman (1971) defines a Hegelian inquiring system to be a system that functions on the premise that greater enlightenment results from the conflict of ideas. The Hegelian dialectic is comprised of three major players. The first player begins the dialectic with a strong conviction about a fundamental thesis. The second player is an observer of the first subject. The observer generates an opposing conviction to the original thesis. In fact, the observer is passionately dedicated to destruction of the first subject's conviction (Churchman, 1971). The final player in the Hegelian dialectic is a bigger mind and an opposition to the conflict between the thesis and the antithesis. This bigger mind synthesizes a new view of the world which absorbs the thesis/antithesis conflict. Synthesis generated by the objective bigger mind acts as guarantor of the system. The promise made is that the movement from thesis-antithesis to synthesis is a soaring to greater heights, to selfawareness, more completeness, betterment, progress (Churchman, 1971). 
According to Mitroff (1974), Hegelian inquiring system is characteristic of conflictual and synthetic systems. They embody the antagonistic and conflict components of human thought. Strengths of the Hegelian inquiring system include: the decision maker is involved in creating knowledge; the process is active; and the conflict can create interest (Mitroff, 1974). Not all personalities, however, are geared to conflict, and this is a major weakness of Hegelian inquiring system. In fact, the cost of debate, without a guarantee of resolution or knowledge creation, is another weakness of this system.

\section{5- the Pragmatist (Singerian IS)}

Churchman (1971) declared two premises when defining the Singerian inquiring system. The first premise establishes a system of measures that specify steps to be followed in resolving disagreements among members of a community; and the second principle guiding Singerian inquiry is the strategy of agreement (Churchman, 1971).

Mitroff (1974) explains the Singerian-Churchmanian inquiring system as characteristic of interdisciplinary, synthetic systems. These systems are holistic in nature and call upon aspects of human knowledge that include: scientific, ethical, and aesthetic (Mitroff, 1974). Mitroff (1974) describes Singerian inquiry as believing that reality is not proven but arrives when enough decision makers are convinced as to what is real. According to Mitroff (1974), both systems differ from Lockean inquirers because they presuppose that raw data is correct input for a system, since the input is based on prior consensus.

Courtney, Croasdell, and Paradice (1998) assert that the purpose of the Singerian inquiring system is to establish knowledge for deciding the proper means for one's end. Knowledge is judged by making improvements which are considered to be measurable. These improvements are considered in seeing what is best for the society. Knowledge should be useful to everyone in the company or organization in order for it to be effective. Employees play a big role in making decisions for the organization. While the Singerian inquiry model provides flexibility and open input into the inquiry process, these attributes may make the decision process unreliable, uncertain, and negative. Although an observer exists within the system, there is no oversight of the observer.
Applications of the Singerian inquiring system are aligned with the Executive Support System (ESS). Examples of this inquiry system can be seen in the Institute of Electrical and Electronics Engineers (IEEE) and the International Organization for Standardization (ISO) standards process. Singerian inquirers pay close attention to new technologies coming out that will make advancements within the organization. A specific example would involve the concurrent and future release of open source code for a particular operating system.

\section{OVERVIEW - 1b: DISCUSSION}

It is necessary not only to learn, but also, to understand how inquiry systems and especially people affect the decision-making process. Organizational learning is the formation of new knowledge that has the opportunity to be molded into creating and influencing new behaviors. Since without personnel such knowledge would not be possible, therefore, organizations must engage in knowledge management to harness the full potential its human capital.

Inquiring systems and knowledge management matched with advances in information technology such as the intranets has increased knowledge. Most of the technology modules have used mathematical models or programmed logic to solve an organization's problems. According to Churchman (1971), these types of systems are most likely suitable for well structured problem situations for which there exists strong consensual position on the nature or the problem situation, and well structured problems for which there exists an analytic formulation with a solution.

There is a degree through where current inquiring systems use methods such as analogies and multimedia technologies offer some communication of meaning. However, a more human centric view of knowledge is needed to have a meaningful view of knowledge creation. Being able to achieve diverse interpretations will enlighten Kantian and Hegelian modes of inquiry for better organizational models. As a result, there must be an understanding of how each of the five inquiry systems affects an organization's decision-making process and impacts the design principles. 
The following table shows a list and progression of the profile generation stage:

Table 1. Characteristics Applied

\begin{tabular}{|c|c|c|c|c|c|}
\hline \multirow[b]{2}{*}{ PEOPLE } & LEIBNIZIAN & LOCKEAN & KANTIAN & HEGELIAN & SINGERIAN \\
\hline & $\begin{array}{l}\text { - Analyst } \\
\text { - Formal logic \& } \\
\text { deduction } \\
\text { - Seeks models \& } \\
\text { formulas theory } \\
\text { and method over } \\
\text { data } \\
\text { - Theory and } \\
\text { method over data }\end{array}$ & $\begin{array}{l}\text { - Realist } \\
\text { - Empirical view } \\
\text { \& induction } \\
\text { - Seeks solution } \\
\text { that meets } \\
\text { current needs } \\
\text { - Data over } \\
\text { theory }\end{array}$ & $\begin{array}{l}\text { - Idealist } \\
\text { - Assimilative or } \\
\text { holistic view } \\
\text { - Seeks ideal solutions } \\
\text { - Data \& theory of } \\
\text { equal value }\end{array}$ & $\begin{array}{l}\text { - Synthesist } \\
\text { - Integrative } \\
\text { view } \\
\text { - Seeks conflict } \\
\text { and synthesis } \\
\text { - Data } \\
\text { meaningless w/o } \\
\text { interpretation }\end{array}$ & $\begin{array}{l}\text { Pragmatist } \\
\text { Eclectic view } \\
\text { Seeks shortest } \\
\text { route to payoff } \\
\text { Interested in } \\
\text { innovation } \\
\text { Any data or } \\
\text { theory that gets } \\
\text { us there }\end{array}$ \\
\hline \multicolumn{6}{|c|}{$\uparrow$} \\
\hline $\begin{array}{c}\text { PROPERTIES OF } \\
\text { LEARNING }\end{array}$ & $\begin{array}{l}\text { - Closed System } \\
\text { - Behavioral } \\
\text { adaptive learning } \\
\text { style } \\
\text { - Syntactic } \\
\text { learning source }\end{array}$ & $\begin{array}{l}\text { - Open system } \\
\text { - Consensual, } \\
\text { generative } \\
\text { learning style } \\
\text { - Pragmatic } \\
\text { learning source }\end{array}$ & $\begin{array}{l}\text { - Open/Closed system } \\
\text { - Cognitive, generative } \\
\text { learning style } \\
\text { - Pragmatic/Semantic } \\
\text { learning source }\end{array}$ & $\begin{array}{l}\text { - Open system } \\
\text { - Generative } \\
\text { double-Loop } \\
\text { learning style } \\
\text { - Semantic } \\
\text { learning source }\end{array}$ & $\begin{array}{l}\text { - Open system } \\
\text { - Generative, do } \\
\text { loop learning } \\
\text { style } \\
\text { - Syntactic } \\
\text { /Pragmatic } \\
\text { learning source }\end{array}$ \\
\hline \multicolumn{6}{|c|}{$\uparrow$} \\
\hline $\begin{array}{c}\text { INQUIRY } \\
\text { SYSTEMS FOR } \\
\text { INFORMATION } \\
\text { RESOURCES } \\
\text { ANALYSIS }\end{array}$ & $\begin{array}{l}\text { - Rational } \\
\text { - Formal-Didactic } \\
\text { - Fact-Net } \\
\text { - ES }\end{array}$ & $\begin{array}{l}\text { - Empirical } \\
\text { - Inductive- } \\
\text { Consensual } \\
\text { - Agreement } \\
\text { - GDSS }\end{array}$ & $\begin{array}{l}\text { - Ideal } \\
\text { - Consensual-Conflict } \\
\text { - Heuristic } \\
\text { - DSS }\end{array}$ & $\begin{array}{l}\text { - Dialectic } \\
\text { - Conflictual- } \\
\text { Synthetic } \\
\text { - Conflict } \\
\text { - IS }\end{array}$ & $\begin{array}{l}\text { - Pragmatic } \\
\text { - Synthetic- } \\
\text { Complex } \\
\text { - Adaptive } \\
\text { - ESS }\end{array}$ \\
\hline
\end{tabular}

\section{OVEVIEW - 2: ADAPTIVE INQUIRY SYSTEMS}

Future systems will likely involve greater human interaction with the systems; it will be necessary to not only create systems for end users, but also to create adaptable systems that consider cultural aspects of the company, stakeholders and clients. Moreover, because of globalization organizations need to be more appreciative of the relationship between structural and cultural change, and be more adaptive to the effects of globalization (Yolles, 2006).

New inquiry paradigms will lead to the creation of new systems based on specific needs related to systems thinking and to the making-decisions processes in general. Here this is accomplished by adapting the main characteristics of the five inquiring

Volume XI, No. 2, 2010 systems: Leibnizian, Lockean, Kantian, Hegelian and Singerian. After analyzing how the system is affected by (corporate) culture, the new systems will adapt a mix of structures to supply specific needs and create tools that best fit the organization and its environment.

As Peter Senge (1990) demonstrates, organizations must have a shared vision and team learning to align the capacities in order to create results. Senge focuses on group problem solving using the systems thinking method in order to convert companies into learning organizations. According to Senge, current systems are failing in considering these aspects or are just simply assuming that they are complying with the mission statement of the organization; however, the purpose of a new model is to inquire at different levels of the organization, internally and externally, to align the resources toward one main objective. It 
means that the model needs to include characteristics of the people at operational levels, middle management, top management, clients, suppliers and related entities. It will be necessary to apply inquiry tools to a sample (keeping an acceptable statistical margin of error) in order to have relevant data of behaviors and characteristics. For Malhotra (2000), Churchman's inquiry paradigm translates to knowledge management. The advantage of this is to have the organization aware of its reality and its desires. In other words, it will be a filter that reflects the actual styles of thinking versus what the organization desires to be. If the corporate culture is pretty much the people making inquiries, then the system will be easily adaptable. However, if diverse styles of thinking are discovered then it will be necessary to create a more complex system.

To answer such situation as these, Bruvold, Parlette, Bramson, \& Bramson (1983) developed an Inquiry Mode Questionnaire that helps identify the type of decision maker the individual most closely resembles. The Inquiry Mode Questionnaire is a set of statements with forced, multiple-choice responses designed to determine an individual's mode of thinking. Strong evidence from both experiential and field research and supported by factor-analysis studies, points to the existence of five styles which define most human modes of thinking. These five styles can, in turn, be directly associated with Churchman's five inquiry system models as summarized in Table 1. The Inquiry Mode Questionnaire measures the extent to which a person uses each of these styles, highlighting the strengths and limitations of each. It measures system thinking rather than personality, and describes key behavioral cues related to each. For example, if the questionnaire indicates that a significant part of the project is rational then the team/system members need to be able to focus on logic. Once the type of decision makers needed have been identified the team as a whole can be assembled.

\section{INTEGRETED INQUIRY SYSTEMS}

Based upon the research reviewed so far, the following model has been designed as shown in Table 2. It is intended as a visual representation of how one might integrate diverse streams of research. Each unit is then reviewed and, as an example, applied to the selection of project team under consideration of PMP guidelines.

Table 2. Integrated Adaptive Inquiry Systems

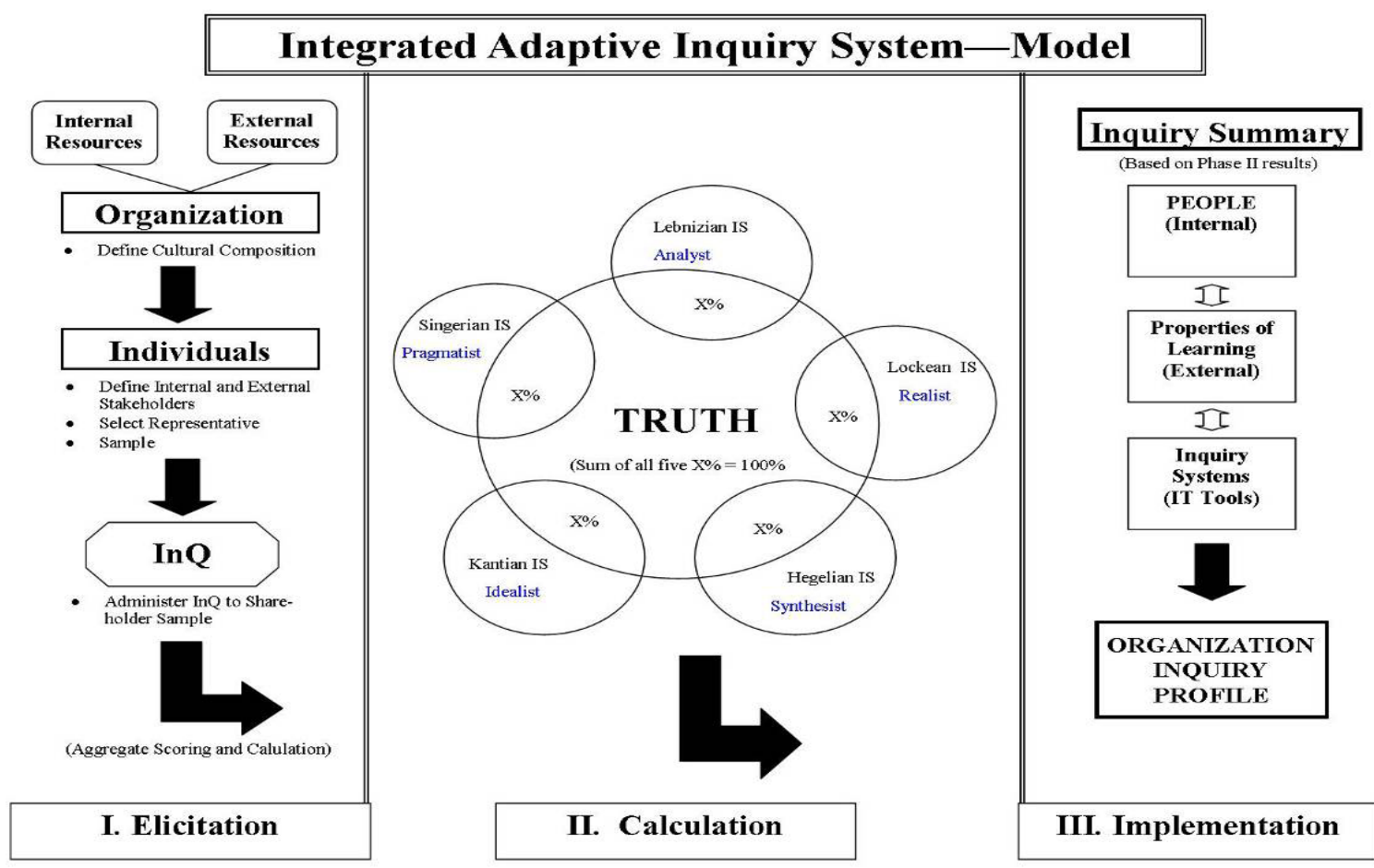

Volume XI, No. 2, 2010 


\section{Phase I: Elucidation}

The model starts with the consideration of cultural factors that involves the characteristics and values of the people involved in the system. As Peter Senge (1993) denotes, organizations must have a shared vision and team learning to align the capacities in order to create results. Current systems are failing in considering these aspects or are just simply assuming that they are complying with the mission statement of the organization; however, the purpose of the model is to inquire at different levels of the organization, internally and externally, to align the resources toward one main objective. It means that the model needs to include characteristics of the people at operational level, middle management, top management, clients, suppliers and related entities. It will be necessary to apply the inquiry tool to a sample (keeping an acceptable statistical margin of error) in order to have relevant data of behaviors and characteristics. The advantage of doing that is to have the organization aware of its reality and its desire; in other words, it will be a filter that reflects the actual styles of thinking versus what the organization desires to be. If the corporate culture is pretty much alike among the people inquired then the system will be easily adaptable, however if diverse styles of thinking are discovered then it will be necessary to create a more complex system. The Inquiry Mode Questionnaire is a questionnaire that will help identify the type of decision maker the individual most closely resembles (Bruvold, Parlette, Bramson, $\&$ Bramson, 1983). For example, if the questionnaire indicates that a significant part is rational hence the system needs to focus on logic, reduce having an exclusive process. Once the type of decision maker has been identified we are able to apply the different inquiry tools.

\section{Phase II: Calculation}

Once all members of the selected sample group have completed the test, the scores from each survey will be combined to determine the overall inquiry makeup of the organization. If multiple groups are surveyed, the Inquiry Mode Questionnaire analysis for each group will be calculated in order for the organization

Volume XI, No. 2, 2010 to determine difference between inquiry preferences between each stakeholder group.

\section{Phase III: Implementation}

Once the aggregate inquiry system model/team is completed and the dominant inquiry styles needed identified, then the appropriate inquiry tools are selected. At this stage, the model first analyzes the organizational needs based on the internal individual characteristics of the predominant inquiry systems. These characteristics originally defined by Churchman (1971) identify concepts and strategies on a more personal level. The second stage of the analysis process reviews concepts based on the external or learning organization level of the organization. The third and final stage of analysis is to review existing IT tools that best facilitate each dominant inquiry system identified.

Once each level of analysis is completed, an organizational profile is generated and tested to tweak the inquiry tools to best fit the needs of the organization. This profile will include internal, external and technological factors relating to each predominant inquiry group identified in the calculation phase of the model. Through the use and evaluation of this model, organization can better determine and facilitate information elicitation from their external and internal resources.

\section{CONCLUSION}

Advances in technology have led to globalization which has made the world smaller. In a smaller world territorial line of economic and cultural ownership has become difficult to discern. Consequently, organizations must find new methods to become flexible with a focus on the human aspects of the organization and integration of technologies must be addressed within the business arena. Looking forward, the next ten years will be critical for corporations to address the human factor of operations if they wish to remain competitive in a global market. This model was developed for such a purpose and is intended to facilitate the focus on the human capital and the human cognitive process. The proposed model demonstrates how the human cognitive processes relate directly to obtaining and retaining essential knowledge and experience within the knowledge management and information inquiry process. Its advantage is that it encourages students and scholars to begin to assemble various avenues of research outside of their discipline and $t$ investigate
Issues in Information Systems 
new avenues of scholarship. It can be investigated as a tool for building more effective project teams.

This research study proposes an inquiry tool that will identify the results that through statistics applications will reveal the percentages of relationships among styles of thinking of the end user of the system. The results of the model reveals a series of assumptions on what characteristics of the systems theories must be utilized in order to fit the business needs and the needs of the end user. By focusing the system design principles more on the end user, it will make future systems more efficient.

\section{REFERENCES}

(Bruvold, 1983) Bruvold, W. H., Parlette, N., Bramson, R. M., \& Bramson, S. J., "An investigation of the item characteristics, reliability, and validity of the inquiry mode questionnaire," Educational and Psychological Measurement, 1983, vol. 43, 2).

(Courtney, 1998) J.F. Courtney, D.T. Croasdell and D.B. Paradice, "Inquiring Organizations," Australian Journal of Information Systems, 1998, vol. 6, 1 .

(Davis, 2006) Christopher J. Davis; Robert M. Fuller; Monica Chiarini Tremblay; Donald J. Berndt, "Communication Challenger in Requirements Elicitation and the Elicitation and the Use of the Repertory Grid Technique", The Journal of Computer Information Systems, 2006, vol. 46, 5.

(Eriksson, 2003) Darek M. Eriksson, "Identification of Normative Sources for Systems Thinking: an Inquiry into Religious Ground-Motives for Systems Thinking Paradigms", Systems Research and Behavioral Science, Nov/Dec 2003, vol. 20, 6, p. 475.

(Hall, 2003) Dianne Hall, David Paradice, James F Courtney, "Building a Theoretical Foundation for a Learning-Oriented Knowledge Management System”, Journal of Information Technology Theory and Application, 2003, vol. 5, 2, p. 63.
(inQ, 2007) "InQ - Your Thinking Profile", InQ Education Materials, 2007, http:/yourthinkingprofile/index.html.

(Malhotra, 2000) "Knowledge Management for the New World of Business", http://www.brint.com/km/whatis.htm.

(McIntyre, 2003) Janet J. McIntyre, "Participatory Democracy: Drawing on C. West Churchman's Thinking When Making Public Policy", Systems Research and Behavioral Science, Nov/Dec 2003.vol. 20, 6, pg. 489.

(Mitroff, 1974) Mitroff, Ian I. The Subjective Side of Science: A Philosophical Inquiry into the Apollo Moon Scientists, Elsevier, Amsterdam 1974.

(Mitroff, 2006) Mitroff, Ian I. Thinking Like an Intellectual Giant: A Tribute West Churchman. $20 \quad$ Jan 2006. http://www.mitroff.net/documents/west_ churchman tribute.pdf.

(Richardson, 2001) Sandra M. Richardson, James F. Courtney, David B. Paradice, "An Assessment of the Singerian Inquiring Organizational Model: Cases from Academia and the Utility Industry", Information Systems Frontiers. Mar 2001, vol. 3,$1 ;$ p. 49.

(Russell, 2006) Bruce D. Russel; Mustafa R. Yilmaz, "Using Gap Analysis to Improve System Acceptance", Information Systems Management, Fall 2006, vol 23, 4.

(Senge, 1990) Peter Senge, The Fifth Discipline: The Art \& Practice of The Learning Organization, Doubleday, New York, 1990.

(Siau, 2006) Keng Siau; Xin Tan, "Using Cognitive Mapping Techniques to Supplement UML and UP Information Retirements Determination", The Journal of Computer Information Systems; 2006, vol. 46, 5.

(Yolles, 2006) Maurice Yolles, Paul Iles, Kaijun Guo , "Culture and transformational change with China's accession to the WTO; The challenge for action research", 
Formal Inquiry Systems

Journal of Technology Management in China, 2006.vol.1, 2, pg. 147. 